\title{
Thousand per Deciliter
}

National Cancer Institute

\section{Source}

National Cancer Institute. Thousand per Deciliter. NCI Thesaurus. Code C73771.

A unit of concentration measurement expressed in thousand(s) per deciliter. 